\title{
Global long-term mapping of surface temperature shows intensified intra-city urban heat island extremes
}

Lorenzo Mentaschi ( $\square$ lorenzo.mentaschi@ec.europa.eu )

European Commission, Joint Research Center, Ispra https://orcid.org/0000-0002-2967-9593

Gregory Duveiller

European Commission Joint Research Centre https://orcid.org/0000-0002-6471-8404

Grazia Zulian

European Commission, Joint Research Center, Ispra

Christina Corbane

European Commission, Joint Research Center, Ispra

Martino Pesaresi

European Commission, Joint Research Center, Ispra https://orcid.org/0000-0003-0620-439X

Joachim Maes

European Commission, Joint Research Center, Ispra

Alessandro Stocchino

The Hong Kong Polytechnic University

Luc Feyen

European Commission, Joint Research Centre (JRC) https://orcid.org/0000-0003-4225-2962

\section{Article}

Keywords: Heat-related Human Illnesses, Short Term Heat Stress, Urbanisation, Heatwaves, Greening

Posted Date: March 10th, 2021

DOI: https://doi.org/10.21203/rs.3.rs-251967/v1

License: (1) (1) This work is licensed under a Creative Commons Attribution 4.0 International License. Read Full License

Version of Record: A version of this preprint was published at Global Environmental Change on January 1st, 2022. See the published version at https://doi.org/10.1016/j.gloenvcha.2021.102441. 

urban heat island extremes

Lorenzo Mentaschi ${ }^{1}$, Grégory Duveiller ${ }^{1}$, Grazia Zulian ${ }^{1}$, Christina Corbane ${ }^{1}$, Martino Pesaresi ${ }^{1}$, Joachim Maes ${ }^{1}$, Alessandro Stocchino ${ }^{2}$, Luc Feyen ${ }^{1}$

${ }^{1}$ : Joint Research Centre (JRC), European Commission, Ispra, Italy.

2: Department of Civil and Environmental Engineering, The Hong Kong Polytechnic University, Hong Kong.

Surface temperatures are generally higher in cities than in rural surroundings ${ }^{1}$. This phenomenon, known as surface urban heat island (SUHI), increases the risk of heat-related human illnesses and mortality ${ }^{2}$. Past global studies analysed this phenomenon aggregated at city scale or over seasonal and annual time periods $s^{3-6}$, while human impacts strongly depend on shorter term heat stress experienced locally. Here we develop a global long-term high-resolution dataset of daytime SUHI as urban-rural surface temperature differences. Our results show that across urban areas worldwide over the period 2003-2020, 3-day SUHI extremes are on average more than twice as high as the warm-season median SUHI, with local exceedances up to $10 \mathrm{~K}$. Over this period, SUHI extremes have increased more rapidly than warmseason medians, and averaged worldwide are now $1.04 \mathrm{~K}$ or $31 \%$ higher compared to 2003 . This can be linked with increasing urbanisation ${ }^{7}$, more frequent heatwaves ${ }^{8}$, and greening of the earth ${ }^{9}$, processes that are all expected to continue in the coming decades ${ }^{10-12}$. Within many cities there are hotspots where extreme SUHI intensity is 10 to $15 \mathrm{~K}$ higher compared to relatively cooler city parts. Given the limited human adaptability to heat stress ${ }^{13}$, our results advocate for mitigation strategies targeted at reducing SUHI extremes in the most vulnerable and exposed city neighbourhoods.

Nowadays, more than half of the human population lives in cities and in the foreseeable future most population growth will be in urban areas ${ }^{10}$. A prominent feature of cities' climate is the Urban Heat Island (UHI), whereby the temperature of urbanized areas noticeably differs from that of rural neighbouring zones $^{14}$, and is generally higher, especially in humid climates when the surroundings are covered by dense vegetation ${ }^{15,16}$. The intensity of UHI as estimated from Land Surface Temperature (LST) is usually referred to as Surface Urban Heat Island (SUHI) ${ }^{3}$.

Studies have found UHI intensity to be linked with background hydro-climatic conditions ${ }^{5,17}$, city size $e^{4,18}$ and morphology ${ }^{19}$, thermodynamic properties of artificial surfaces and construction materials ${ }^{3-5,20}$, and the density and characteristics of vegetation ${ }^{17,21}$. Because most urban climate studies are performed on limited and not always representative empirical cases, it is difficult to intercompare their results and to reach general quantitative conclusions on causal relationships ${ }^{22}$.

A more comprehensive database of global urban surface warming is needed for identifying emerging spatiotemporal patterns and areas for remediation. Large-scale UHI studies have focused primarily on coarse-grained representations of UHIs, where the thermal behaviour is lumped spatially over urban centres ${ }^{23,24}$ and temporally over seasonal ${ }^{5}$ or annual ${ }^{3}$ time scales. As a consequence, these fail to capture UHI peaks that are localised in space and time, and that are better represented in fine-scale studies ${ }^{25-27}$. Characterising temporal fluctuations is of foremost importance to assess the real threat posed to human health by urban heat, as phenomena such as heat waves can often last only few days ${ }^{28-30}$. Moreover, UHI intensity can vary between different parts of the same city ${ }^{22}$ depending on their morphology and on the 
thermodynamic proprieties of their constitutive elements (e.g. densely built-up areas vs green areas). Finally, spatial averaging can dilute the intensity of the hazard felt locally.

Here we estimate daytime SUHI as the difference in LST between urban pixels and their rural surroundings at $1 \times 1 \mathrm{~km}$ globally with a daily time step for the period 2003-2020. We use LST retrieved from satellite observations of the MODIS Aqua mission and built-up surfaces of the Global Human Settlements Layer $(\mathrm{GHSL})^{31}$ to delineate urban pixels. We focus our analysis on the warm season, when urban heat is more likely to represent a risk to human health ${ }^{3,4,21}$. As the highest effects typically appear within 3 days of extreme heat event onset ${ }^{30}$ we consider 3-day averaged values of SUHI. For each urban pixel we calculate: (1) the warm-season median $\left(S U H I_{\text {seas }}\right)$, which represents a central estimate of the SUHI in the warm season for each year between 2003-2020; (2) the 1-year maximum $\left(S U H I_{1 y}\right)$, which represents the maximum 3-day SUHI in the warm season for each year between 2003-2020; and (3) the 18-year maximum $\left(S U H I_{18 y}\right)$, which represents the maximum 3-day SUHI estimated over all the warm seasons between 20032020.

\section{Short-term maxima versus temporally aggregated SUHI}

Across all urban areas worldwide over the period 2003-2020, the space-time median $S U H I_{\text {seas }}$ is $2.5 \mathrm{~K}$ (Fig. 1 and Table S1). This corroborates earlier global ${ }^{3,4}$ and regional ${ }^{15}$ studies that report annually and seasonally averaged SUHI intensities of few degrees. Short-term maxima show to be significantly higher. With a global 18-year space-time median $S U H I_{1 y}$ of $4.0 \mathrm{~K}$, annual 3-day peaks of SUHI are on average $1.5 \mathrm{~K}$ more intense than the seasonal SUHI. Under extreme conditions of urban surface warming, represented by $S U H I_{18 y}$, this rises to nearly $6.0 \mathrm{~K}$, or more than a doubling of the seasonal SUHI intensities.

There is large variation around the central global estimates. Extreme SUHI intensity $\left(S U H I_{18 y}\right)$ can reach beyond $16 \mathrm{~K}$, with a global $95^{\text {th }}$ percentile of $11.3 \mathrm{~K}$. This is about $4 \mathrm{~K}$ higher than the corresponding statistics for the warm-season median SUHI (SUHI $\left.I_{\text {seas }}\right)$. At pixel level, $S U H I_{1 y}$ exceeds $S U H I_{\text {seas }}$ by a maximum of $>7 \mathrm{~K}$, and by $4.2 \mathrm{~K}$ in $5 \%$ of urban pixels. For $S U H I_{18 y}$, the pixel-wise differences with $S U H I_{\text {seas }}$ are even larger and reach $6.9 \mathrm{~K}$ in $5 \%$ of urban pixels, with a maximum difference $>12 \mathrm{~K}$. While synergies between heat waves and SUHI have not been fully understood and remain subject of debate ${ }^{32}$, several studies have shown amplified urban warming under heat waves, especially in temperate regions ${ }^{33}$. Hence, during times when background heat is most pronounced, strongly intensified SUHI can considerably add to the heat stress in cities.

Eighteen percent of urban pixels present negative values of $S U H I_{\text {seas }}$, whilst this fraction is much reduced if maxima are considered: $S U H I_{1 y}$ is negative in $7 \%$ of the pixels and $S U H I_{18 y}$ is negative in $2.3 \%$ of the pixels. This suggests that cities, or parts thereof, that generally act as heat sinks (i.e., urban areas cooler than their surroundings ${ }^{4}$ ) may occasionally behave as heat islands (Fig. S1). 


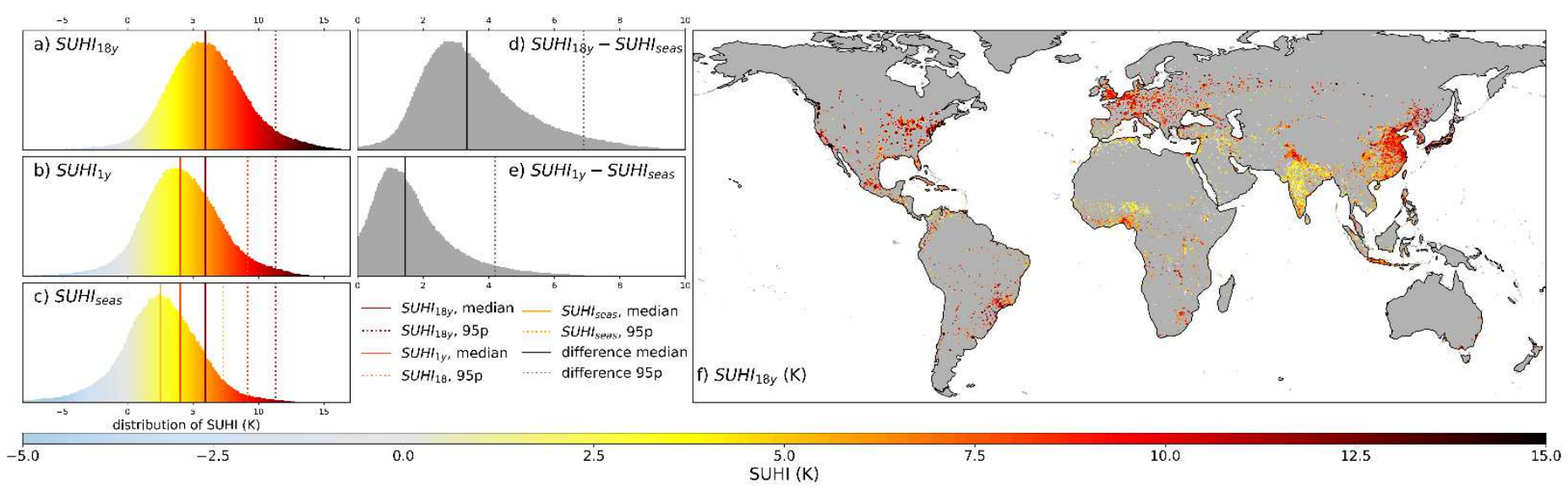

Fig. 1 | Global distribution of warm-season SUHI indices. a, Histogram across urban pixels worldwide of the pixel warm-season 3day SUHI maximum over the 18 years analysed $\left(S U H I_{18 y}\right)$. b. Histogram across all urban pixels worldwide of the pixel median of the yearly warm-season 3-day SUHI maxima $\left(S U H I_{1 y}\right)$ of the 18 years analysed. c, Histogram across all urban pixels worldwide of the pixel warm-season SUHI median $\left(S U H I_{\text {seas }}\right)$ over the 18 years analysed. $\mathbf{d}$, Histogram across all urban pixels worldwide of the pixel difference between $S U H I_{18 y}$ and the 18-year median $S U H I_{\text {seas }}$. e, Histogram across all urban pixels worldwide of the pixel difference between $S U H I_{1 y}$ and the 18-year median $S U H I_{\text {seas }}$. The solid and dashed vertical lines in the histograms in a-e represent the median and $95^{\text {th }}$ percentile over all urban pixels worldwide for the respective indices and differences therein. $f$, Global map of warm-season 3-day SUHI maximum over the 18 years analysed $\left(S U H I_{18 y}\right)$ in urban pixels. Urban pixels are defined as $1 \times 1 \mathrm{~km}$ built-up pixels enclosed within the spatial boundaries of Functional Urban Areas (FUA). FUA are cities and their surroundings and nearly four billion people live in the 9028 FUAs worldwide.

The global map of $S U H I_{18 y}$ (Fig. 1f) shows strong spatial heterogeneity in extreme surface urban warming, but some geographic patterns can be observed linked with background climate. $S U H I_{18 y}$ is generally higher at mid-high latitudes in areas characterized by temperate and humid conditions, where dense and aerodynamically rough vegetation in rural areas results in higher evapotranspiration rates and convection efficiency compared to their urban counterparts. In drier regions, evapotranspiration and convection efficiency of low stature natural vegetation outside cities is lower, resulting in smaller or even negative UHI intensities ${ }^{5,16}$. Monsoon and equatorial regions also show mostly milder $S U H I_{18 y}$ intensities, which relates to a levelling of the precipitation effect on evapotranspiration above $1500 \mathrm{~mm} \mathrm{yr}^{-1}$ and decreasing urban warming intensities for warmer climates ${ }^{5}$. Apart from the considerably higher values found for $S H_{H} I_{18 y}$ compared to $\mathrm{SUHI}_{\text {seas }}$, the large-scale patterns in $\mathrm{SUHI}_{18 \mathrm{y}}$ are in general consistent with those observed for $S_{U H} I_{\text {seas }}$ (see Fig. S2a) and found in earlier studies for city-scale seasonal means s $^{3,5}$. We notice that areas characterized by strong climatic variability during the warm season, e.g. monsoon regions, usually experience a stronger difference between seasonal averages and maxima (Fig. $\mathbf{S 2} \mathbf{b}, \mathbf{c}$ ) that can be linked to more distinctive seasonal hysteretic cycles of urban and rural temperatures ${ }^{34}$.

\section{Long-term trends in SUHI maxima}

We find that across all urban centres worldwide SUHI maxima $\left(S U H I_{1 y}\right)$ have increased on average by nearly $1.04 \mathrm{~K}$, or $0.06 \mathrm{~K} \mathrm{yr}^{-1}$, between 2003 and 2020 (Fig. 2). Eastern Asia shows the strongest rise of $0.12 \mathrm{~K}$ $\mathrm{yr}^{-1}$, which can be linked to the rapid urbanisation in the region ${ }^{10}$. This is exemplified by the city of Tianjin, where the urban area nearly quadruplicated between 1980 and $2010^{35}$ and the trend in $S U H I_{1 y}$ locally exceeds $0.3 \mathrm{~K} \mathrm{yr}^{-1}$ (Fig. 2n). Despite the general trend of urbanisation and consequent urban warming in the region ${ }^{36}$, some cities in Eastern Asia show distinctive signs of declining population in inner-city areas ${ }^{37}$. This can cause a downward trend in SUHI in shrinking city parts, such as in Seoul, where after 2000 the population decline and requalification of the central business district led to reduced SUHI intensities in the 
city centre ${ }^{38}$ (Fig. $\mathbf{2 m}$ ). While the process of city shrinking is emerging in Asian cities, it has been observed since many decades in US and Europe ${ }^{39}$, and even in developing countries a number of large cities have been affected by this phenomenon ${ }^{40}$. In many cases this is accompanied by suburbanisation, which shifts the burden to newly built-up suburbs where extreme SUHI can rise rapidly.

Despite the strong urbanisation in Southern and South Eastern Asia, but also in sub-Saharan Africa ${ }^{10}$, the rate of increase in extreme daytime $\mathrm{UHI}$ intensity is two to four times lower compared to Eastern Asia. This conforms to the effects of background climate on urban surface warming, which is more pronounced in temperate regions compared to more arid and tropical regions. In the very hot and dry climate of the Middle East and North Africa the trend is negative as urbanisation generally results in heat sinks.

Extreme urban surface warming has increased less strongly also in North America ( $\left.0.03 \mathrm{~K} \mathrm{yr}^{-1}\right)$, Europe (0.03 $\left.\mathrm{K} \mathrm{yr}^{-1}\right)$, South-America $\left(0.05 \mathrm{~K} \mathrm{yr}^{-1}\right)$, and Oceania $\left(0.05 \mathrm{~K} \mathrm{yr}^{-1}\right)$. With already more than $70 \%$ of population living in urban centres in these regions ${ }^{41}$, urbanisation in recent decades has been lower compared to strongly developing areas. However, at present these regions still show the highest extreme SUHI intensities, with average $S U H I_{1 y}$ above $6 \mathrm{~K}$ for cities in North-America, close to $5.5 \mathrm{~K}$ in Oceania and Europe, and around $5 \mathrm{~K}$ in South-America.

Extreme SUHI intensities show in general a stronger increasing trend in time compared to median warmseason values (Fig. S3), but there are strong geographic differences. In South-America, $S U H I_{1 y}$ has increased by $0.05 \mathrm{~K} \mathrm{yr}^{-1}$ compared to $0.02 \mathrm{~K} \mathrm{yr}^{-1}$ for $S U H I_{\text {seas }}$, implying extreme urban surface warming has increased more than double the rate of the seasonal values. Also in Europe and Russia extreme SUHI intensities have clearly risen more. In sub-Saharan Africa there is no trend in $S U H I_{\text {seas }}$ while $S U H I_{1 y}$ has increased by nearly $0.5 \mathrm{~K}$ between 2003 and 2020. In South Asia, $S U H I_{\text {seas }}$ has become slightly less negative, while $S U H I_{1 y}$ increased from $1.4 \mathrm{~K}$ to nearly $2 \mathrm{~K}$ on average over the region (Fig. 2).

A generally upward trend in temporally-aggregated urban warming has been reported before, with strong variations between cities ${ }^{23,24}$. This is driven by the continued urbanisation around the world ${ }^{7,10}$, the greening of natural vegetation ${ }^{9}$ and cropland $^{42}$ in rural areas, and modulated by background climate ${ }^{5,16}$ and artificial dynamics ${ }^{38,43}$. The more pronounced trend in $S U H I_{1 y}$ compared to $S U H I_{\text {seas }}$ suggests a higher sensitivity of extreme SUHI to urbanisation. Current understanding does not indicate that global warming directly enhances differences in rural-urban warming ${ }^{22}$, but the observed increase in heatwave days almost everywhere since the $1950 \mathrm{~s}^{8}$ and possible synergies between heat waves and $\mathrm{SUH} \mathrm{I}^{33}$ can partially explain the stronger increase in SUHI extremes. The amplification of greenness-climate feedbacks during extreme climate conditions ${ }^{44}$ further suggests stronger positive effects of greening of non-urban areas on extreme SUHI compared to temporally-aggregated urban warming. 

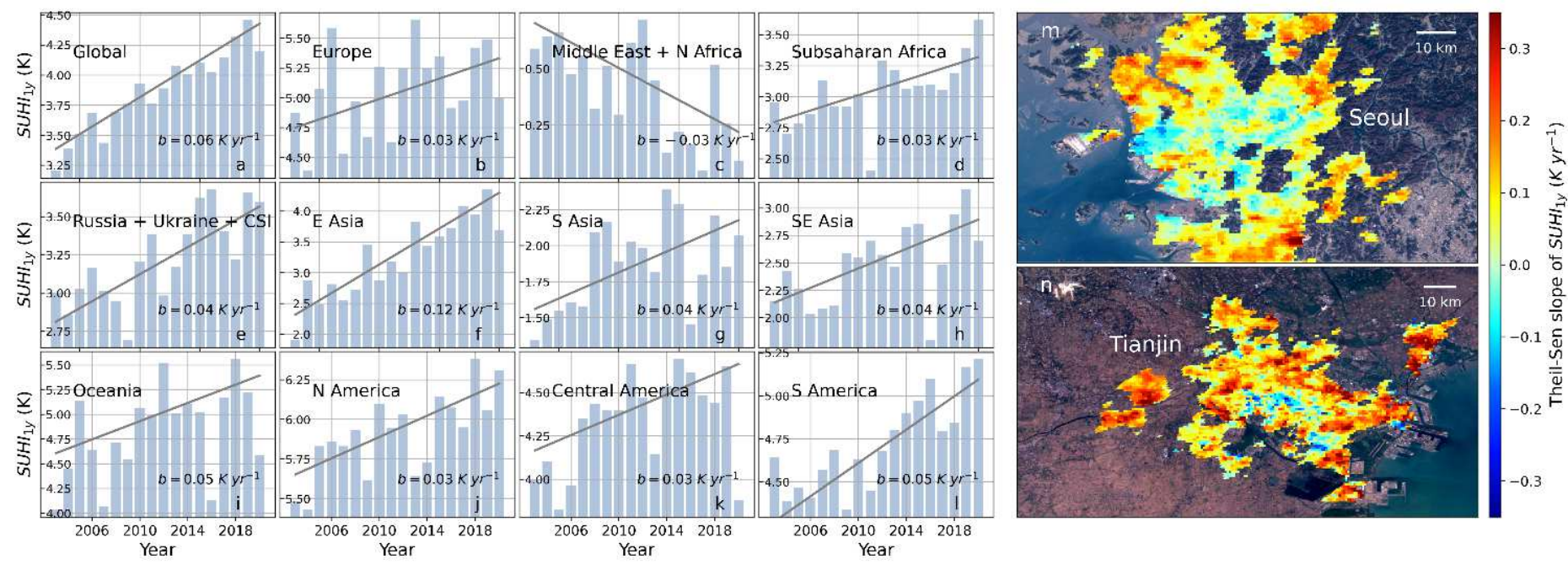

Fig. 2 | Trend in yearly SUHI maxima of the warm season. Trend of $S U H I_{1 y}$ for the globe (a) and in different macro-areas (b-I). In each panel the Theil-Sen slope ${ }^{7}$ is reported (coefficient b). For the globe and all macro-areas the slope is significant beyond the $95 \%$ confidence. $\mathbf{m}-\mathbf{n}$, Maps of the trend (in K $\mathrm{rr}^{-1}$ ) in Seoul $(\mathbf{m}$ ) and Tianjin (n). Figure S4 shows the pixels built-up between 2000 and 2015 according to GHSL.

\section{A zoom on city scale variability}

A zoom on 14 megacities spread over the different continents reveals highly diversified intra-city pictures of extreme surface urban warming (Fig. 3). Across these urban centres, $S U H I_{18 y}$ varies on average by $12.8 \mathrm{~K}$

(Fig. 3, Table S2), with the highest spatial variability observed in Tokyo $\left(0.9 \leq S U H I_{18 y} \geq 17.6 \mathrm{~K}\right)$ and New York $\left(0.1 \leq S U H I_{18 y} \geq 16 \mathrm{~K}\right)$, and the lowest in Paris $\left(2.1 \leq S U H I_{18 y} \geq 12.7 \mathrm{~K}\right)$ and London $\left(0.8 \leq S U H I_{18 y} \geq 10 \mathrm{~K}\right)$.

While each city has its own unique combination of climate, geography, and internal structure, some common patterns can be observed. Hotspots are often found in industrial parts of cities, where waste heat, the use of dark construction material and absence of vegetation can result in high SUHI intensities ${ }^{45}$. For example, in New York particularly high values of $S_{U H} H_{18 y}$ can be observed South of Newark, where the international airport, a railroad and other industrial facilities are located (Fig. S5). In Paris the hotspots of $S U H I_{18 y}$ are east of Saint-Denise and near Chevilly Larue, both areas with large industrial complexes (Figure S6). Similar examples can be found for all of the examined cities (Fig. 2).

In Mexico City high values of $S U H I_{18 y}$ can be found in areas characterised by a high concentration of slums, such as Ciudad Nezahualcoyotl and Iztapalapa (Figures S7). This corroborates the link between the chaotic, dense and unregulated urbanisation typical of slums and intense heat exposure ${ }^{46}$. Combined with poverty, poor housing conditions and little access to cooling options this poses serious health threats to people ${ }^{47}$.

Urban parks and green zones often correspond to relatively cooler areas. This can be observed, for example, for the forest areas in Hachioji ${ }^{48}$, at the Sayama lake, and in the Chiyoda park in Tokyo, the Bois de Boulogne and the Bois de Vincennes in Paris, Hampstead Heath in London, La Tourette Park in New York

(Fig. S8, S6, S9, S5). Water bodies within the city can also dampen $S_{U H} I_{18 y}$ intensity, as exemplified by the River Thames in London (Fig. S9). These findings confirm the important role of urban green and water in the mitigation of $\mathrm{SUHI}^{17}$. In coastal cities, proximity to the sea can mitigate $S U H I_{18 y}$, as can be observed in Buenos Aires, Sydney and Jakarta, but sea breeze cooling effects can be inhibited by tall buildings on the seafront or inner city ${ }^{22}$. that warm up fast in clear sky conditions, and scarce vegetation and evapotranspiration cooling. Partially 

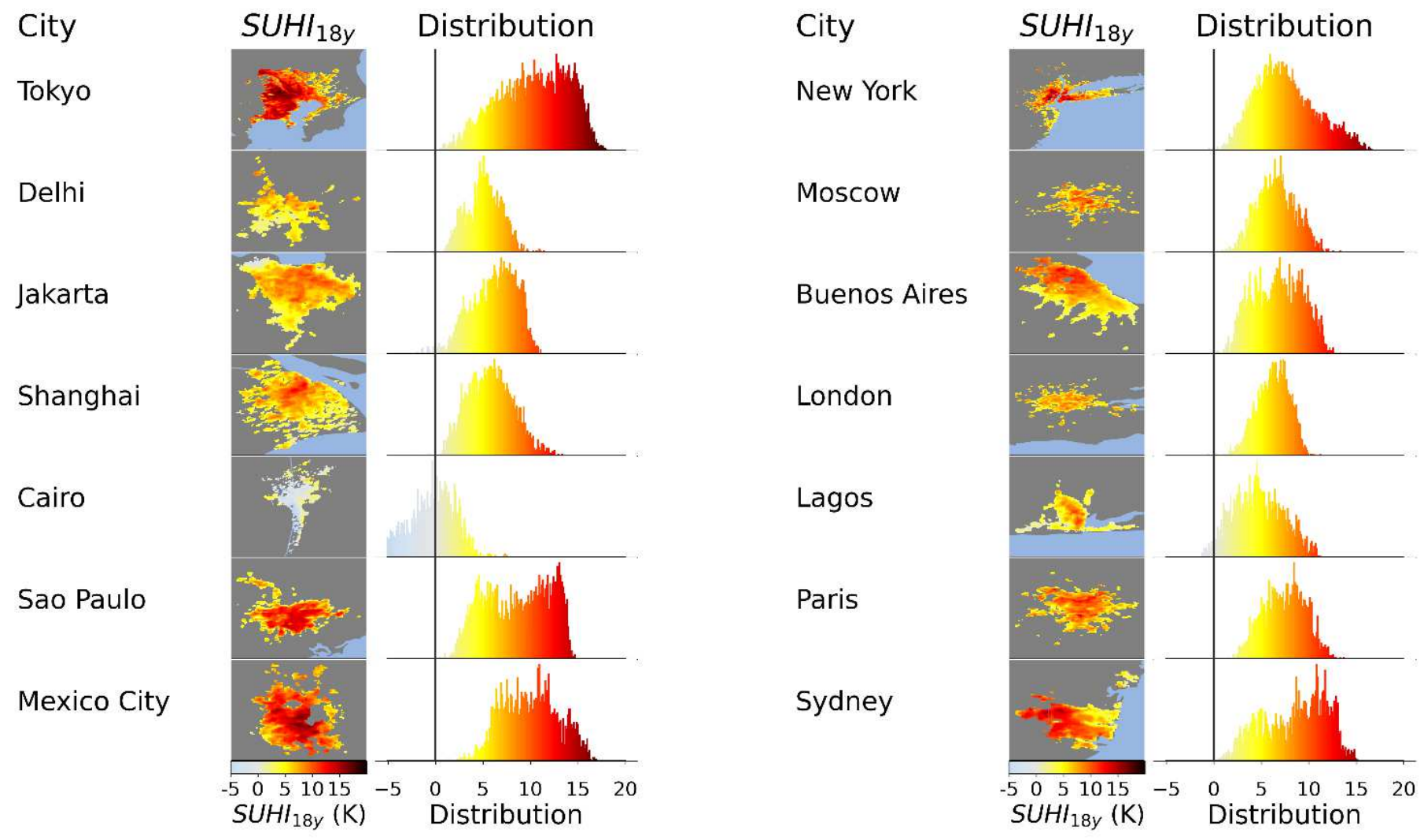

Fig. 3 | Distribution of warm-season extreme SUHI in megacities. Maps (left panels) and histograms (right panels) of warm-season 3-day SUHI maximum over the 18 years analysed $\left(\mathrm{SUHI}_{18 y}\right)$. Considered are all urban pixels within the Functional Urban Areas for each of the 14 world megacities.

\section{Conclusions}

Our results reveal relevant spatiotemporal variability in SUHI that is not captured by previous global coarser-grained spatiotemporal representations of SUHI ${ }^{3,5}$. Short-term (3-day) SUHI maxima can be several degrees higher than seasonally estimated SUHI, with differences up to $10 \mathrm{~K}$ and more, while they can vary by an order of magnitude within cities. While SUHI extremes are already intensifying, continued urbanisation ${ }^{10}$, a growing number of slum dwellers, and a further rise in the frequency and intensity of hot spells with global warming ${ }^{49}$, could elevate urban heat stress and consequent health risk to unprecedented levels in the most exposed and vulnerable city neighbourhoods in the near future. The management of extreme heat in cities will therefore be a major challenge to improve health and the urban environment. Global urban science can support this process by building fine-grained UHI models applicable across urban settlements worldwide, including under-studied regions and smaller cities ${ }^{50}$, in order to forge new knowledge on urban warming extremes and their drivers. The dataset produced in this study, available on the Google Earth Engine, offers this opportunity. 


\section{Bibliography}

204 1. Oke, T. R. The energetic basis of the urban heat island. Q. J. R. Meteorol. Soc. (1982).

2. Sera, F. et al. How urban characteristics affect vulnerability to heat and cold: A multi-country analysis. Int. J. Epidemiol. (2019). doi:10.1093/ije/dyz008

3. Peng, S. et al. Surface urban heat island across 419 global big cities. Environ. Sci. Technol. (2012). doi:10.1021/es2030438

4. Clinton, N. \& Gong, P. MODIS detected surface urban heat islands and sinks: Global locations and controls. Remote Sens. Environ. (2013). doi:10.1016/j.rse.2013.03.008

5. Manoli, G. et al. Magnitude of urban heat islands largely explained by climate and population. Nature (2019). doi:10.1038/s41586-019-1512-9

6. Chakraborty, T. \& Lee, X. A simplified urban-extent algorithm to characterize surface urban heat islands on a global scale and examine vegetation control on their spatiotemporal variability. Int. J. Appl. Earth Obs. Geoinf. 74, 269-280 (2019).

7. Gong, P. et al. Annual maps of global artificial impervious area (GAIA) between 1985 and 2018 . Remote Sens. Environ. 236, 111510 (2020).

8. Perkins-Kirkpatrick, S. E. \& Lewis, S. C. Increasing trends in regional heatwaves. Nat. Commun. (2020). doi:10.1038/s41467-020-16970-7

9. Yao, R., Wang, L., Huang, X., Gong, W. \& Xia, X. Greening in Rural Areas Increases the Surface Urban Heat Island Intensity. Geophys. Res. Lett. 46, 2204-2212 (2019).

10. United Nations, Department of Economic and Social Affairs, P. D. The World's Cities in 2018. World's Cities 2018 - Data Bookl. (ST/ESA/SER.A/417) (2018).

11. Dosio, A., Mentaschi, L., Fischer, E. M. \& Wyser, K. Extreme heat waves under $1.5^{\circ} \mathrm{C}$ and $2{ }^{\circ} \mathrm{C}$ global warming. Environ. Res. Lett. 13, (2018).

12. Zhao, Q., Zhu, Z., Zeng, H., Zhao, W. \& Myneni, R. B. Future greening of the Earth may not be as large as previously predicted. Agric. For. Meteorol. 292-293, 108111 (2020).

13. Sherwood, S. C. \& Huber, M. An adaptability limit to climate change due to heat stress. Proc. Nat/. Acad. Sci. U. S. A. (2010). doi:10.1073/pnas.0913352107

14. Arnfield, A. J. Two decades of urban climate research: a review of turbulence, exchanges of energy and water, and the urban heat island. Int. J. Climatol. 23, 1-26 (2003).

15. Zhou, D. et al. Satellite remote sensing of surface urban heat islands: Progress, challenges, and perspectives. Remote Sensing (2019). doi:10.3390/rs11010048

16. Zhao, L., Lee, X., Smith, R. B. \& Oleson, K. Strong contributions of local background climate to urban heat islands. Nature (2014). doi:10.1038/nature13462

17. Weng, Q., Lu, D. \& Schubring, J. Estimation of land surface temperature-vegetation abundance relationship for urban heat island studies. Remote Sens. Environ. (2004). 
18. Li, X., Zhou, Y., Asrar, G. R., Imhoff, M. \& Li, X. The surface urban heat island response to urban expansion: A panel analysis for the conterminous United States. Sci. Total Environ. (2017). doi:10.1016/j.scitotenv.2017.06.229

19. Zhou, B., Rybski, D. \& Kropp, J. P. The role of city size and urban form in the surface urban heat island. Sci. Rep. (2017). doi:10.1038/s41598-017-04242-2

20. Chakraborty, T. \& Lee, X. A simplified urban-extent algorithm to characterize surface urban heat islands on a global scale and examine vegetation control on their spatiotemporal variability. Int. J. Appl. Earth Obs. Geoinf. (2019). doi:10.1016/j.jag.2018.09.015

21. Zhou, D., Zhao, S., Liu, S., Zhang, L. \& Zhu, C. Surface urban heat island in China's 32 major cities: Spatial patterns and drivers. Remote Sens. Environ. (2014). doi:10.1016/j.rse.2014.05.017

22. Masson, V., Lemonsu, A., Hidalgo, J. \& Voogt, J. Urban Climates and Climate Change. Annu. Rev. Environ. Resour. 45, 411-444 (2020).

23. Ajaaj, A. A., Mishra, A. K. \& Khan, A. A. Urban and peri-urban precipitation and air temperature trends in mega cities of the world using multiple trend analysis methods. Theor. Appl. Climatol. (2018). doi:10.1007/s00704-017-2096-7

24. Varquez, A. C. G. \& Kanda, M. Global urban climatology: a meta-analysis of air temperature trends (1960-2009). npj Clim. Atmos. Sci. (2018). doi:10.1038/s41612-018-0042-8

25. Wang, J., Zhou, W. \& Wang, J. Time-Series Analysis Reveals Intensified Urban Heat Island Effects but without Significant Urban Warming. Remote Sens. 11, 2229 (2019).

26. Armson, D., Stringer, P. \& Ennos, A. R. The effect of tree shade and grass on surface and globe temperatures in an urban area. Urban For. Urban Green. 11, 245-255 (2012).

27. Tzavali, A., Paravantis, J. P., Mihalakakou, G., Fotiadi, A. \& Stigka, E. Urban heat island intensity: A literature review. Fresenius Environ. Bull. (2015).

28. Meehl, G. A. \& Tebaldi, C. More intense, more frequent, and longer lasting heat waves in the 21st century. Science (2004). doi:10.1126/science.1098704

29. Nitschke, M., Tucker, G. R. \& Bi, P. Morbidity and mortality during heatwaves in metropolitan Adelaide. Med. J. Aust. (2007). doi:10.5694/j.1326-5377.2007.tb01466.x

30. Gao, J. et al. Impact of extreme high temperature on mortality and regional level definition of heat wave: A multi-city study in China. Sci. Total Environ. (2015). doi:10.1016/j.scitotenv.2014.10.028

31. Corbane, C. et al. Convolutional neural networks for global human settlements mapping from Sentinel-2 satellite imagery. Neural Comput. Appl. (2020). doi:10.1007/s00521-020-05449-7

32. Scott, A. A., Waugh, D. W. \& Zaitchik, B. F. Reduced Urban Heat Island intensity under warmer conditions. Environ. Res. Lett. (2018). doi:10.1088/1748-9326/aabd6c

33. Zhao, L. et al. Interactions between urban heat islands and heat waves. Environ. Res. Lett. (2018). doi:10.1088/1748-9326/aa9f73

34. Manoli, G., Fatichi, S., Bou-Zeid, E. \& Katul, G. G. Seasonal hysteresis of surface urban heat islands. Proc. Natl. Acad. Sci. 117, 7082-7089 (2020).

35. Wu, W., Zhao, S., Zhu, C. \& Jiang, J. A comparative study of urban expansion in Beijing, Tianjin and Shijiazhuang over the past three decades. Landsc. Urban Plan. 134, 93-106 (2015).

36. Yang, Q., Huang, X. \& Tang, Q. The footprint of urban heat island effect in 302 Chinese cities: 
Temporal trends and associated factors. Sci. Total Environ. (2019). doi:10.1016/j.scitotenv.2018.11.171

37. Liu, Z., Liu, S. \& Song, Y. Understanding urban shrinkage in China: Developing a multi-dimensional conceptual model and conducting empirical examination from 2000 to 2010. Habitat Int. (2020). doi:10.1016/j.habitatint.2020.102256

38. Hong, J.-W., Hong, J., Kwon, E. E. \& Yoon, D. K. Temporal dynamics of urban heat island correlated with the socio-economic development over the past half-century in Seoul, Korea. Environ. Pollut. 254, 112934 (2019).

39. Martinez-Fernandez, C. et al. Shrinking cities in Australia, Japan, Europe and the USA: From a global process to local policy responses. Prog. Plann. (2016). doi:10.1016/j.progress.2014.10.001

40. State of the world's cities 2008/2009: Harmonious cities. State of the World's Cities 2008/2009: Harmonious Cities (2012). doi:10.4324/9781849772624

41. Carneiro Freire, S. M. et al. Atlas of the Human Planet 2019. (2019). doi:10.2760/014159

42. Chen, C. et al. China and India lead in greening of the world through land-use management. Nat. Sustain. 2, 122-129 (2019).

43. Nichol, J. E., Choi, S. Y., Wong, M. S. \& Abbas, S. Temperature change and urbanisation in a multinucleated megacity: China's Pearl River Delta. Urban Clim. 31, 100592 (2020).

44. Forzieri, G., Alkama, R., Miralles, D. G. \& Cescatti, A. Satellites reveal contrasting responses of regional climate to the widespread greening of Earth. Science 356, 1180-1184 (2017).

45. Portela, C. I., Massi, K. G., Rodrigues, T. \& Alcântara, E. Impact of urban and industrial features on land surface temperature: Evidences from satellite thermal indices. Sustain. Cities Soc. (2020). doi:10.1016/j.scs.2020.102100

46. Wang, J., Kuffer, M., Sliuzas, R. \& Kohli, D. The exposure of slums to high temperature: Morphologybased local scale thermal patterns. Sci. Total Environ. 650, 1805-1817 (2019).

47. Teare, J. et al. Dwelling Characteristics Influence Indoor Temperature and May Pose Health Threats in LMICs. Ann. Glob. Heal. 86, (2020).

48. Tran, H., Uchihama, D., Ochi, S. \& Yasuoka, Y. Assessment with satellite data of the urban heat island effects in Asian mega cities. Int. J. Appl. Earth Obs. Geoinf. (2006). doi:10.1016/j.jag.2005.05.003

49. Russo, S. et al. Half a degree and rapid socioeconomic development matter for heatwave risk. Nat. Commun. (2019). doi:10.1038/s41467-018-08070-4

50. Acuto, M. Give cities a seat at the top table. Nature (2016). doi:10.1038/537611a

51. Wan, Z. \& Li, Z. L. MODIS land surface temperature and emissivity. in Remote Sensing and Digital Image Processing 11, 563-577 (2011).

52. Corbane, C. et al. Convolutional Neural Networks for Global Human Settlements Mapping from Sentinel-2 Satellite Imagery. arXiv e-prints (2020).

53. Gorelick, N. et al. Google Earth Engine: Planetary-scale geospatial analysis for everyone. Remote Sens. Environ. 202, 18-27 (2017).

54. Hart, L. G., Larson, E. H. \& Lishner, D. M. Rural Definitions for Health Policy and Research. Am. J. Public Health 95, 1149-1155 (2005).

55. Pekel, J.-F., Cottam, A., Gorelick, N. \& Belward, A. S. High-resolution mapping of global surface water and its long-term changes. Nature 1-19 (2016). doi:10.1038/nature20584 
56. Stewart, I. D. A systematic review and scientific critique of methodology in modern urban heat island literature. International Journal of Climatology (2011). doi:10.1002/joc.2141

57. USGS. SRTM Topography. SRTM Doc. 2.1, http://dds.cr.usgs.gov/srtm/version_1/Documentatio (2009).

58. Hartmann, D. L. Global physical climatology: Second Edition. Global Physical Climatology: Second Edition (2015). doi:10.1016/C2009-0-00030-0

59. Schiavina, M., Moreno-monroy, A., Maffenini, L. \& Veneri, P. GHSL-OECD Functional Urban Areas. (2019). doi:10.2760/67415

60. Dijkstra, L., Poelman, H. \& Veneri, P. The EU-OECD definition of a functional urban area. OECD Reg. Dev. Work. Pap. Éditions OCDE (2019). doi:doi.org/10.1787/d58cb34d-en

61. Moreno-Monroy, A. I., Schiavina, M. \& Veneri, P. Metropolitan areas in the world. Delineation and population trends. J. Urban Econ. 103242 (2020). doi:10.1016/j.jue.2020.103242

62. Song, Y., Achberger, C. \& Linderholm, H. W. Rain-season trends in precipitation and their effect in different climate regions of China during 1961-2008. Environ. Res. Lett. (2011). doi:10.1088/17489326/6/3/034025

63. Dash, S. K., Kulkarni, M. A., Mohanty, U. C. \& Prasad, K. Changes in the characteristics of rain events in India. J. Geophys. Res. Atmos. (2009). doi:10.1029/2008JD010572

64. Nicholson, S. E., Some, B. \& Kone, B. An analysis of recent rainfall conditions in West Africa, including the rainy seasons of the $1997 \mathrm{El}$ Nino and the 1998 La Nina years. J. Clim. (2000). doi:10.1175/1520-0442(2000)013<2628:AAORRC>2.0.CO;2

65. Theil, H. A Rank-Invariant Method of Linear and Polynomial Regression Analysis. in (1992). doi:10.1007/978-94-011-2546-8_20

\section{Methods}

Mapping land surface temperature and built-up surfaces

Daily data of Land Surface Temperature (LST) were taken from the MODIS Aqua product of global Land Surface Temperature/Emissivity (MYD11A1 version 6 $6^{1}$ ) for the period from January 2003 until December 2020. This 1-km resolution dataset was chosen for its quasi-daily coverage of the world surface. Our focus in on daytime SUHI and satellite Aqua was preferred to Terra because it provides measurements in the early afternoon, approximately at the time of highest solar radiation and maximum daily surface temperature.

The extent of built-up surfaces used to define urban and non-urban areas has also been mapped by means of satellite imagery classification. We used the most recent version of the Global Human Settlement Layer $\left(\mathrm{GHSL}^{2}\right)$, based on Sentinel-2. It is based on convolution neural network modelling for pixel-wise image classification of built-up areas and provides at $10-\mathrm{m}$ resolution the probability (between 0 and $100 \%$ ) of a pixel to belong to the class built-up for the year 2018.

The handling of the large datasets and the analysis of SUHI as described below was carried out on the Google Earth Engine ${ }^{3}$. 


\section{Estimation of SUHI}

SUHI is defined as the difference in LST between urban and non-urban or rural areas. The term rural, which acquires distinct semantics in different literary contexts, is broadly used in scientific literature to indicate any type of non-urban territory ${ }^{4}$. Here it identifies any pixel that is not built-up. The resolution of the builtup information from GHSL $(10 \mathrm{~m})$ is higher than that of the LST from MODIS (1 km). For each MODIS 1-km pixel the mean built-up probability was estimated for the year 2018 by averaging the probability values of the 10-m GHSL pixels contained inside of it. Then, MODIS pixels with a mean probability $>15 \%$ were considered as built-up. The minimum threshold suggested to be considered as built-up is a probability of $20 \%^{5}$. However, in our case the main objective is the exclusion of built-up pixels from the computation of the surrounding non-urban temperature, which justifies the choice of a lower cut-off. The detection of the built-up pixels was carried out solely for 2018, the reference year of the latest GHSL dataset.

Although water bodies can dampen SUHI in nearby and downwind locations, they should be excluded from the surrounding rural area considered in the calculation of SUHI, as that would artificially inflate SUHI values. For the detection of water bodies, we used the Global Surface Water (GSW) dataset ${ }^{6}$ available at 30-m resolution. For each MODIS pixel, the percentage of surface occupied by water was estimated from GSW, and 1-km pixels with water presence $>15 \%$ were excluded from the computation. The latest available raster of water presence was employed (year 2019).

The intensity of the SUHI was estimated from LST by means of a kernel-based approach whereby the same procedure was applied to all the urban pixels of all the imagery available in MYD11A1. For each 1-km builtup pixel the LST was obtained directly from MODIS and is denoted by $L S T_{\text {urban }}$. The corresponding value for the rural surroundings ( $L S T_{\text {rural }}$ ), was computed as the median LST of all non-built-up non-water pixels within a kernel consisting of a $70 \mathrm{~km}$-side square centred on the built-up pixel. This size guarantees that in the majority of the cities, for any built-up pixel there are at least 500 non-built-up pixels for the computation of $L S T_{\text {rural }}$. The only city where this condition is violated in a part of the urban area is Shanghai, for which a double-size kernel (a $140 \mathrm{~km}$-side square) was used. The SUHI was then computed as the difference between the $L S T$ of the built-up pixel ( $\left.L S T_{\text {urban }}\right)$ and the surrounding non-urban area ( $\left.L S T_{\text {rrural }}\right)$ :

$$
S U H I=L S T_{\text {urban }}-L S T_{\text {rural }}
$$

Elevation is an important factor that influences LST and placing urban and rural pixels at similar elevation is required to isolate the effect of urbanisation on $\mathrm{SUHI}^{7}$. Consequently, the temperature data of pixels at different altitude should be corrected before being able to compare them. To account for the effects of surface relief we used the Shuttle Radar Topography Mission data provided by the U.S. Geological Survey (USGS SRTM ${ }^{8}$ ) at $100-\mathrm{m}$ resolution. The LST of each pixel was corrected to the mean altitude of the $70 \mathrm{~km}$ size square centred in the pixel (140 km in proximity of Shanghai). The adjustment was done considering an environmental lapse rate of $-6.5 \mathrm{~K}$ per $1000 \mathrm{~m}$ of altitude ${ }^{9}$.

The kernel-based approach comes with advantages with respect to techniques relying on a definition of urban area based on population or other socioeconomic indicators, in terms of robustness and reproducibility. It has only 2 degrees of freedom: the cut-off to define the built-up pixels (15\% of built-up probability), and the kernel size ( $70 \mathrm{~km}$, everywhere with the exception of Shanghai where the kernel size is $140 \mathrm{~km}$ ). Furthermore, its application to all the built-up pixels, including the ones not located in urban areas delineated based on socioeconomic indicators, enables the possible future study of the urban-non urban continuum. 


\section{SUHI in Functional Urban Areas}

Though the estimation of SUHI was carried out and stored for all built-up 1-km pixels worldwide, we report spatial and temporal statistics over built-up pixels enclosed within the spatial boundaries of 9028 Functional Urban Areas (FUA $)^{10}$. FUA are cities and their surroundings, composed of high-density urban centres with at least 50 thousand people plus their surrounding commuting zones ${ }^{11}$. They are used here to identify urban contexts, leaving out small and isolated extra-urban centres made up of few built-up pixels. Today $53 \%$ of the world population (3.9 billion people) live inside FUA ${ }^{12}$. Overall, more than 1,200,000 1-km urban pixels (i.e. built-up pixels located in a FUA) where considered in the discussion.

\section{SUHI during periods of heat stress}

The analysis presented in this manuscript focuses on SUHI during the warm season, when human heat stress is typically highest ${ }^{13-15}$. Past studies used a temperate-zone definition of summer, i.e., the months of June, July, August (JJA) for the Northern Hemisphere (NH), the months of December, January, February (DJF) for the Southern Hemisphere (SH) ${ }^{13,16-18}$. However, in some tropical and subtropical areas, these months may partially coincide with the raining season ${ }^{19-21}$. This reduces the likelihood of intense heatwaves and the number of reliable observations of SUHI. Therefore, we defined the warm season as:

- For temperate and polar regions (latitude above $35^{\circ} \mathrm{N} / \mathrm{S}$ ), the months of JJA/DJF in the NH/SH.

- For tropical and subtropical regions $\left(10^{\circ} \mathrm{N} / \mathrm{S}<\right.$ latitude $\left.<35^{\circ} \mathrm{N} / \mathrm{S}\right)$, the months of April, May, June, July, August, September (AMJJAS) in the NH, the months of October, November, December, January, February, March (ONDJFM) in the SH.

- For areas closer than $10^{\circ}$ to the equator, characterized by persistent warm conditions, the whole year was considered.

Human impacts of heat are highest when conditions of high temperature last for several days ${ }^{22-24}$. In each urban pixel the daily estimates of SUHI during the warm season were therefore temporally aggregated by means of a 3-day moving average. From the resulting time-averaged time series, we estimated the following statistics for each urban pixel: (1) the warm-season medians $\left(S U H I_{\text {seas }}\right)$, which represents a central estimate of the SUHI in the warm season for each year between 2003-2020; (2) the 1-year maxima $\left(S U H I_{1 y}\right)$, which represents the maximum 3-day SUHI in the warm season for each year between 20032020; and (3) the 18-year maximum ( $\left.S U H I_{18 y}\right)$, which represents the maximum 3-day SUHI estimated over all the warm seasons between 2003-2020. The space-time statistics (medians, $95^{\text {th }}$ percentiles, maxima, $\%$ above zero) of $S U H I_{\text {seas }}, S U H I_{1 y}$, shown in Table $\mathrm{S} 1$ and presented in the manuscript, were estimated by computing a pixelwise median between the annual values, and then considering the resulting spatial distribution. For $S U H I_{18 y}$, which is not defined along a time axis, the statistics were estimated directly from the spatial raster.

Trends were estimated on the annual values of $S_{U H} I_{1 y}$ and $S U H I_{\text {seas }}$ for the world and 11 macro-regions (Europe, Middle East + North Africa, Sub-Saharan Africa, Russia + Ukraine + Commonwealth of Independent States (CIS), East Asia, South Asia, Southeast Asia, Oceania, North America, Central America, and South America). $S U H I_{1 y}$ and $S U H I_{\text {seas }}$ estimates at pixel level were first aggregated to macro-region by taking the spatial median over urban pixels in FUA of the considered macro-region. The trend's slope was then estimated on the macro-region annual $S U H I_{1 y}$ and $S U H I_{\text {seas }}$ values using a Theil-Sen estimator ${ }^{25}$. 


\section{Figures}

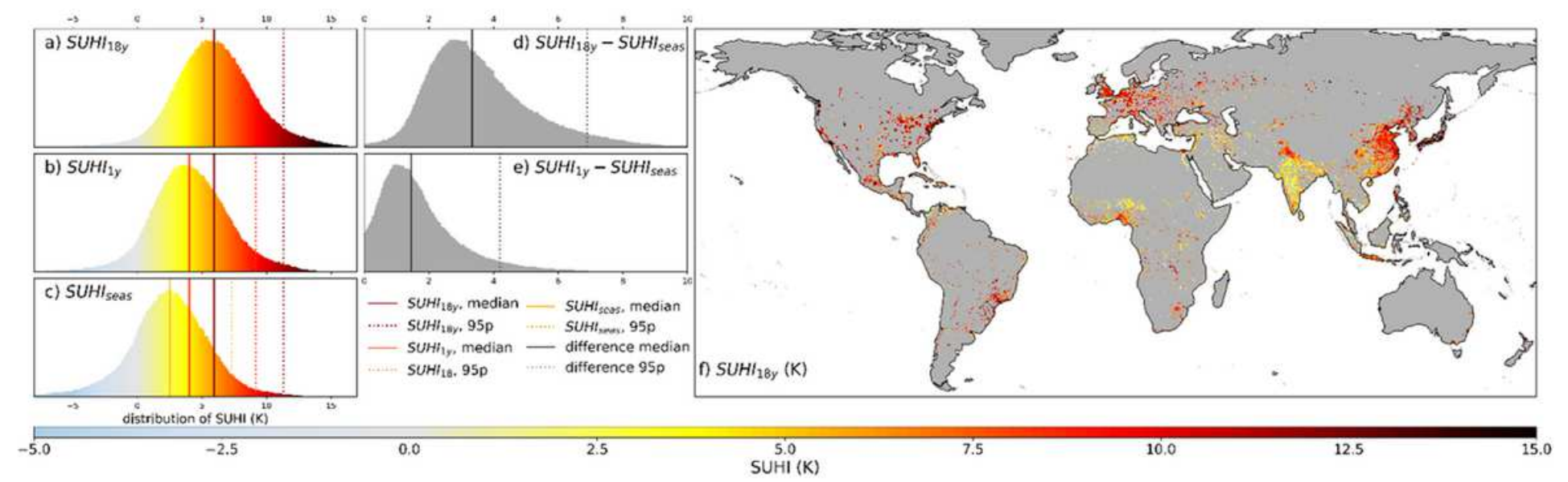

\section{Figure 1}

Global distribution of warm-season SUHI indices. a, Histogram across urban pixels worldwide of the pixel warm-season 3-day SUHI maximum over the 18 years analysed (SUHI_18y). b, Histogram across all urban pixels worldwide of the pixel median of the yearly warm-season 3-day SUHI maxima (SUHI_1y) of the 18 years analysed. c, Histogram across all urban pixels worldwide of the pixel warm-season SUHI median (SUHI_seas) over the 18 years analysed. d, Histogram across all urban pixels worldwide of the pixel difference between SUHI_18y and the 18-year median SUHI_seas. e, Histogram across all urban pixels worldwide of the pixel difference between SUHI_1y and the 18-year median SUHI_seas. The solid and dashed vertical lines in the histograms in a-e represent the median and 95th percentile over all urban pixels worldwide for the respective indices and differences therein. $f$, Global map of warm-season 3-day SUHI maximum over the 18 years analysed (SUHI_18y) in urban pixels. Urban pixels are defined as $1 \mathrm{x} 1$ $\mathrm{km}$ built-up pixels enclosed within the spatial boundaries of Functional Urban Areas (FUA). FUA are cities and their surroundings and nearly four billion people live in the 9028 FUAs worldwide. Note: The designations employed and the presentation of the material on this map do not imply the expression of any opinion whatsoever on the part of Research Square concerning the legal status of any country, territory, city or area or of its authorities, or concerning the delimitation of its frontiers or boundaries. This map has been provided by the authors. 

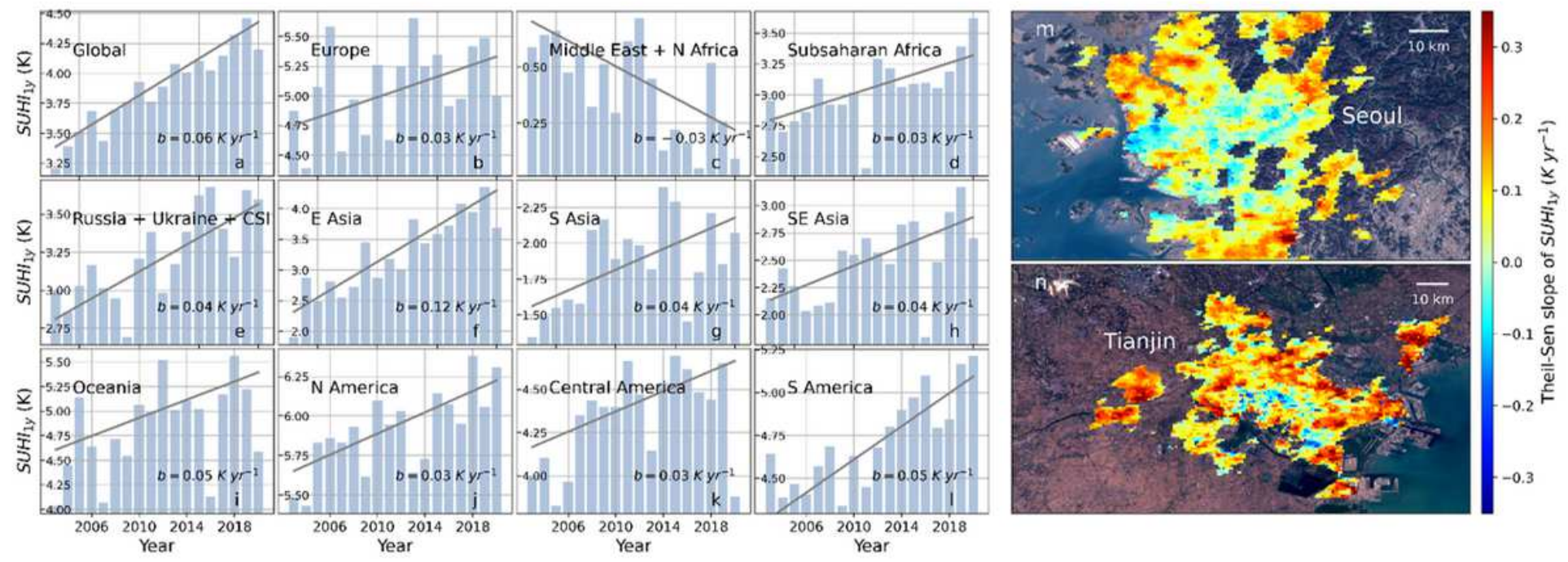

Figure 2

Trend in yearly SUHI maxima of the warm season. Trend of SUHI_1y for the globe (a) and in different macro-areas (b-l). In each panel the Theil-Sen slope7 is reported (coefficient b). For the globe and all macro-areas the slope is significant beyond the $95 \%$ confidence. $m-n$, Maps of the trend (in K yr-1) in Seoul (m) and Tianjin (n). Figure S4 shows the pixels built-up between 2000 and 2015 according to GHSL. Note: The designations employed and the presentation of the material on this map do not imply the expression of any opinion whatsoever on the part of Research Square concerning the legal status of any country, territory, city or area or of its authorities, or concerning the delimitation of its frontiers or boundaries. This map has been provided by the authors. 


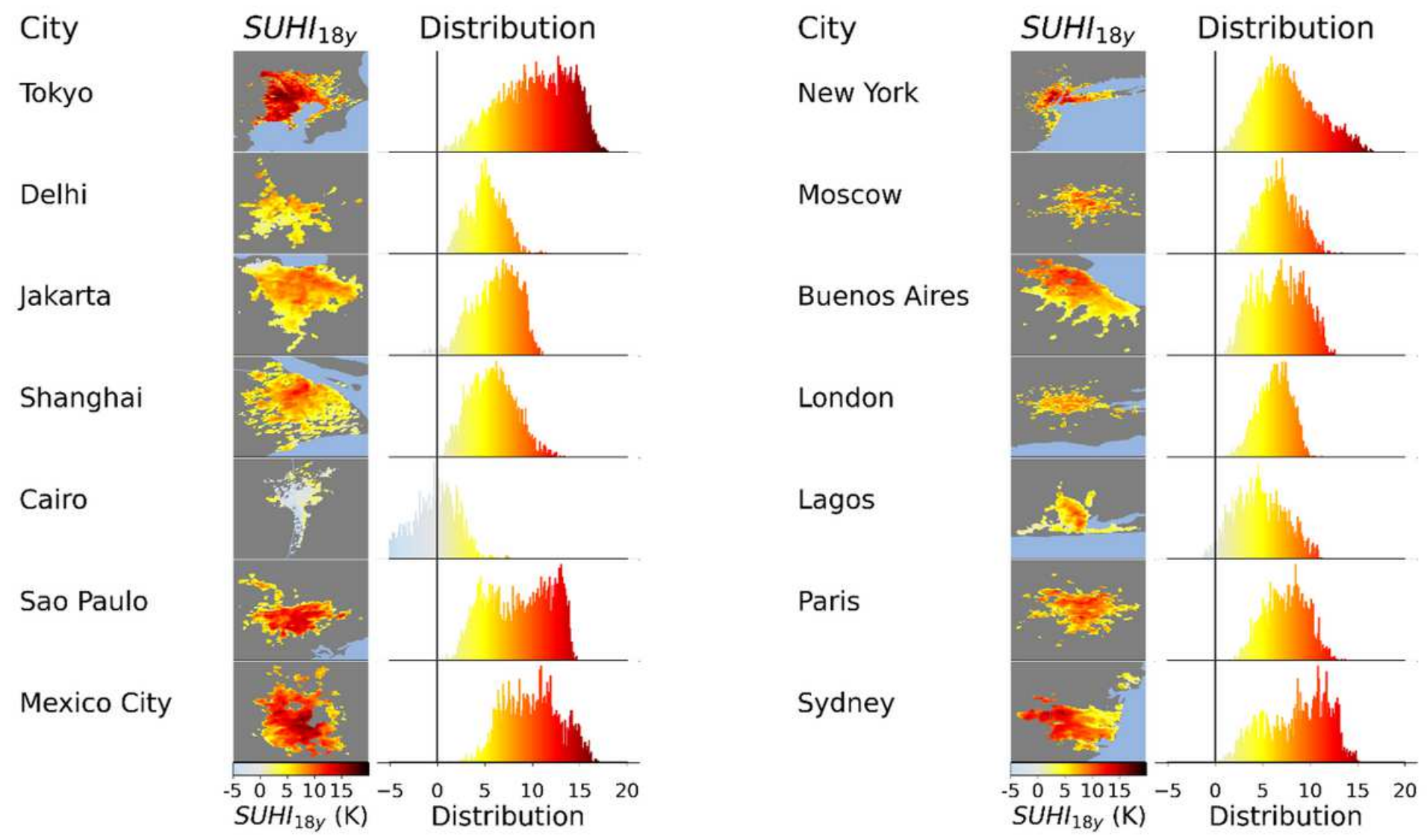

\section{Figure 3}

Distribution of warm-season extreme SUHI in megacities. Maps (left panels) and histograms (right panels) of warm-season 3-day SUHI maximum over the 18 years analysed (SUHI_18y). Considered are all urban pixels within the Functional Urban Areas for each of the 14 world megacities. Note: The designations employed and the presentation of the material on this map do not imply the expression of any opinion whatsoever on the part of Research Square concerning the legal status of any country, territory, city or area or of its authorities, or concerning the delimitation of its frontiers or boundaries. This map has been provided by the authors.

\section{Supplementary Files}

This is a list of supplementary files associated with this preprint. Click to download.

- uhiDraftNatureSubmissionSI.docx 